\title{
Nummular headache - three years later: What happened
}

\author{
Domenico Chirchiglia, Pasquale Chirchiglia, Domenico La Torre \\ Department of Medical and Surgical Sciences, University of Catanzaro, Italy
}

\begin{abstract}
Nummular headache is a very rare form of epilepsy. The main characteristics are the intensity of pain and rarity. The case we have described is the third one discovered in Italy, while only 200 cases have been reported worldwide. The response to drugs is not always effective. We treated the patient with a combination of palmitoylethanolamide and topiramate, the treatment was successful and the patient had a significant improvement in headache. Today, after 3 years we report the case, we are describing the course of headache. Three years later, the patient is almost free from painful attacks and shows a qualitatively better life. In addition, the improvement of headache has allowed the reduction of the topiramate, to avoid the appearance of adverse effects.
\end{abstract}

Keywords: headache, nummular headache, palmitoylethanolamide

\section{INTRODUCTION}

Nummular headache $(\mathrm{NH})$ is a disorder characterized by continuous or intermittent head pain, localyzed in a round area of the scalp, generally 1 to 6 $\mathrm{cm}$ in diameter. Pain is usually mild or moderate in intensity, but some patients suffer severe acute exacerbations with disabling pain. The International Classification of Headache Disorders (ICHD) has broadly classified headache disorders into primary and secondary. Primary headache disorders include migraine, tension-type headache, and other primary headache disorders. Nummular headache is comprised among other primary headache disorders. without an identifiable underlying etiology $[1,2]$. Secondary cases are reported due tumors, skin lesions, infections. Regarding therapy, gabapentin and beta-blockers are considered slightly more effective than others, as well as botulinum toxin type A considered the most effective as prophylaxis.

\section{CASE REPORT}

We want to tell our experience with nummular headache, which occurred about three years ago, concerning the third case in those times found in Italy. During these years, the patient was always checked and was subjected to computed cerebral tomography, and magnetic reasonance imaging, which were normal. The case concerned a 57-yearold woman with a long history of superficial cranial pain in a rounded area of the right parietal region described as a coin. Pain was described as a daily, subcontinuous one, with periods of exacerbation during which it was severe and disabling. The patient underwent preventive therapy with topiramate, at a dose of $50 \mathrm{mg} \times 2 / \mathrm{d}$ tablet and $600 \mathrm{mg} / \mathrm{d}$ tablet of palmitoylethanolamide (PEA) reporting a slight improvement in pain rating scales - visual analogue scale (VAS), numeric rating scale (NRS), visual rating scale (VRS). After an observation period of 2 months topiramate was reduced first at $50 \mathrm{mg} / \mathrm{d}$ tablet and then at $25 \mathrm{mg} / \mathrm{d}$ tablet, maintaining the same dose of PEA. Further improvement of pain as well as in the scale parameters (1 on VAS, 1 on NRS, and no or mild pain on VRS). Currently, three years later, the patient reports occasional mild pain. Treatment has not been changed. 


\section{DISCUSSION}

Nummular headache is considered a very rare headache. Pareira first described it in 2002; today two-hundred cases have been described in the literature. Female/male prevalence ratio is $2: 1$. Pain covers a round area of the scalp, shaped like a coin (lat. nummulus, moneta). Head pain often is moderate, in some cases is severe [3,4]. Clinical and experimental data have shown that nummular headache is a peripheral disorder. In fact, stimulation of scalp structures reproduces this pain. Transdiploic and intradiploic nerves, connecting scalp to dura mater, are thought to be involved in the pathophysiology of nummular headache [5]. Recent studies suggest that an alteration of these nerves produces a circumscribed area of head pain [4]. Therefore nummular headache belongs to so-called epicranias. Epicrania include headaches that arise from scalp including epicranial nerves. For mild to moderate pain, NSAIDs and analgesics are used, while in severe pain prophylaxis therapy with gabapentin, pregabalin and tricyclic antidepressants showed alternating results. Botulinum toxin has shown good results $[6,7]$. The considerations to be made on the nummular headache, we studied, are the following: after three years our patient reported only some occasional episode of mild pain compared to three years earlier when the pain was severe and continuous. The use of palmitoylethanolamide, a substance involved in the processes of neuroinflammation, has proved effective, leading to a reduction of topiramate $[8,9]$. This combination confirmed the peripheral hypothesis of the neuropathic pain of nummular headache. We recommend the topiramate/PEA combination having seen how the two drugs have proven effective and safe. The neuropathic characteristics of pain in nummular headache are endorsed by the excellent response to drugs used in neuropathies.

\section{CONCLUSION}

The nummular headache is not very known for the rarity. We believe that the treatment must be effective even if personalized, as demonstrated by our experience.

Conflict of interest: none declared Financial support: none declared

\section{REFERENCES}

1. Cuadraro ML, López-Ruiz P, Guerrero ÁL. Nummular headache: An update and future prospects. Expert Rev Neurother. 2018;18(1):9-19.

2. Headache Classification Subcommittee of the International Headache Society. The international classification of headache disorders, 3rd edition (beta version). Cephalalgia. 2013; 33(9):629-808.

3. Guerrero AL, Cortijo E, Herrero-Velázquez $\mathrm{S}$ et al. Nummular headache with and without exacerbations: comparative characteristics in a series of 72 patients. Cephalalgia. 2012;32(8):649-653.

4. Guerrero AL, Cuadrado ML, García-García ML et al. Bifocal nummular headache: A series of 6 new cases. Headache. 2011; 51(7):1161-1166.

5. Pareja JA, Pareja J, Barriga FJ et al. Nummular headache: A prospective series of 14 new cases. Headache. 2004;44:611-614.

6. Ruscheweyh R, Buchheister A, Gregor N, Jung A, Evers S. Nummular headache: six new cases and lancinating pain attacks as possible manifestation. Cephalalgia. 2010;30(2):249-253.

7. 7. Wilhour D, Ceriani CEJ, Nahas SJ. Nummular Headache. Curr Neurol Neurosci Rep. 2019;19(6):26.

8. 8. Liu Y, Wei T. First three cases of scalp temperature change in symptomatic areas affected by nummular headache: A case report. BMC Neurol. 2018;18(1):223.

9. 9. Chirchiglia D, Della Torre A, Signorelli F, Volpentesta G, Guzzi G, Stroscio CA, Deodato F, Gabriele D, Lavano A. Administration of palmitoylethanolamide in combination with topiramate in the preventive treatment of nummular headache. Int Med Case Rep J. 2016;18;9:193-5. 